\title{
Review essay/Samlingsrecension
}

David Budgen. British Children's Literature and the First World War. Representations Since 1914. London: Bloomsbury Academic, 2018 (222 s.)

Lissa Paul, Rosemary Ross Johnston \& Emma Short (red.). Children's Literature and Culture of the First World War. New York: Routledge, 2016 (347 s.)
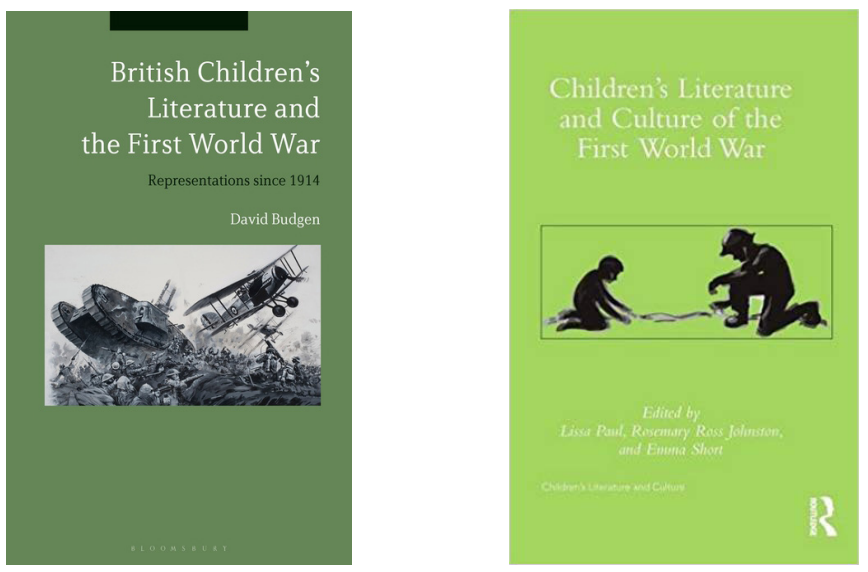

Även om hundra år har passerat sedan det första världskriget avslutades i ett vapenstillestånd klockan 11 den 11 november 1918 har dess attraktionskraft inte upphört att verka på författare och filmmakare. I anslutning till jubileumsåret 2018 producerades åtminstone två filmer som utforskar "The Great War" i olika genrer: Peter Jacksons dokumentära och tekniskt avancerade They Shall Not Grow Old (2018) och Leo Schermans frånstötande skräckfilm Trench 11 (2017). Till detta kommer de historiska romaner och naturligtvis den forskningslitteratur som belyser kriget från olika perspektiv, såsom exempelvis Bjarne S. Bendtsens Mellem fronterne. Første verdenskrigs aftryk i dansk litteratur og kultur 1914-1939 (2018), Tim Daytons American Poetry and the First World War (2018) och Peter Englunds Stridens skönhet och sorg 1917 (2017). Det finns säkerligen en rad skäl till varför filmmakare och författare gång på gång graviterar mot denna avgörande händelse i det tidiga 1900-talets historia. Till de mer vägande hör rimligtvis att det första världskriget innebar slutet på den gamla världen samtidigt som dess inverkan på vår egen tid är både omfat-

(C2019 Olle Widhe. This is an Open Access article distributed under the terms of the Creative Commons Attribution-Noncommercial 3.0 Unported License (http://creativecommons.org/ licenses/by-nc/3.0/), permitting all non-commercial use, distribution, and reproduction in any medium, provided the original work is properly cited.

Citation: Barnboken - tidskrift för barnlitteraturforskning/Barnboken - Journal of Children's Literature Research, Vol. 42,2019 http://dx.doi org/10.14811/clr.v42i0.385 
tande och svår att överblicka. Enligt den inflytelserika historikern Eric Hobsbawm angav det första världskriget rentav den grundläggande riktningen för hela det efterföljande 1900-talet. Utan det första världskriget skulle inte samma grogrund för Hitlers nationalism ha funnits, och utan det andra världskriget hade det kalla kriget antagligen inte delat världen. Dagens Europa skulle kort sagt ha sett annorlunda ut i mer än ett avseende.

Det första världskriget utgör en viktig händelse även i relation till barnböckerna och deras historia. Att det i samband med 100-årsjubileet av kriget publicerades två böcker som behandlar sambandet mellan det första världskriget och barnlitteraturen är därför välkommet. David Budgens litteratursociologiskt orienterade monografi British Children's Literature and the First World War. Representations Since 1914 (2018) och Lissa Pauls, Rosemary Ross Johnstons och Emma Shorts mer tvärvetenskapliga antologi Children's Literature and Culture of the First World War (2016) får nog sägas tillhöra de till dags dato tyngsta bidragen till den anglosaxiska forskningen på fältet. Genom att analysera barnlitteraturens förhållande till det första världskriget i olika tider ger de en mångfacetterad bild av krigets betydelse för barnbokens utveckling, men också av hur synen på barnet och barnlitteraturens uppgift har förändrats över tid. Bland de många barnboksförfattare som har utforskat detta krig på senare år är engelsmannen Michael Morpurgo tveklöst en av de mest betydande. I sina böcker War Horse (1982) - utgiven på svenska med titeln Joey 1985 och senare med titeln Warhorse 2012 - och Listen to the Moon (2014) - utgiven i svensk översättning med titeln Lyssna till månen 2017 - skildrar han fängslande hur kriget griper in i människors livsöden och påverkar dem i generation efter generation. Därför är det passande att Morpurgo får spela en viktig roll i båda undersökningarna. I Children's Literature and Culture of the First World War har han rentav författat ett personligt förord som ger en stämningsfull ingång till hela antologin.

David Budgen är historiker vid University of Kent och i sin systematiska och välavvägda monografi undersöker han i åtta korta men koncentrerade kapitel hur det första världskriget framställs i barnlitteraturen, från 1914 fram till i dag. Budgen utnyttjar ett omfattande material för sina analyser, allt från seriemagasin och pojk- respektive flickböcker, till skolböcker och tidskrifter. Hans inledande påpekande att litteraturen spelar en viktig roll för våra uppfattningar om krig i allmänhet och det första världskriget i synnerlighet är inte orimligt, men bör sannolikt förstås i relation till att bokens författare är historiker. Därmed legitimerar han barnlitteraturen som ett studieobjekt 
värdigt en fackhistoriker intresserad av det första världskriget som fenomen snarare än som ett ämne för den mer barnbokshistoriskt intresserade. Barnlitteraturen har, hävdar Budgen vidare, inte bara haft betydelse för hur kriget kommit att uppfattas, utan har också påverkat den bild av manligt hjältemod som möjliggjorde själva mobiliseringen inför kriget. Det ligger säkert en hel del sanning också i detta påstående, även om det inte underbyggs med argument från den befintliga forskningen - exempelvis genom hänvisningar till Elizabeth Goodenoughs och Andrea Immels Under Fire. Childhood in the Shadow of War (2008) - utan med författaren Mark Twains onekligen dramatiska, men under alla omständigheter tveksamma, påstående att Walter Scott genom sina idealiserande skildringar av krig bör göras ansvarig för det amerikanska inbördeskriget.

Oavsett Budgens ingång till sitt ämne är det intressant att följa honom när han skärskådar kriget som motiv i den litteratur som publicerades runt 1914 och som sedan ledde fram till skildringarna av det första världskriget. Det är också givande att ta del av hans resonemang om hur de unga läsarna sannolikt avvisade vissa delar av berättelserna för att engagera sig desto mer $i$ andra. Sammanfattningsvis lyckas Budgen på ett koncist sätt visa att olika konkurrerande bilder av det första världskriget omsattes i barnlitteraturen redan under mellankrigstiden. I ett särskilt läsvärt kapitel tar han upp hur kriget framställdes i böcker som riktade sig till flickor - även flickor och kvinnor förväntades göra sin plikt. Efter det andra världskrigets slut förändrades sedan skildringarna av det första världskriget på ett mer övergripande sätt, till att mer sysselsätta sig med hur kriget påverkade vardagen i England. Det som nu stod på spel var inte först och främst det manliga hjältemodet vid fronten, utan det engelska folkets stoicism och patriotism, vilket erbjöd nya sätt att tolka konflikten.

Antologin Children's Literature and Culture of the First World War har ett betydligt snävare historiskt fokus. Om Budgen försöker ge en heltäckande bild av hur det första världskriget framställs i brittiska barnböcker från 1914 och framåt begränsar sig Children's Literature and Culture of the First World War till barnlitteratur och barnkultur som producerades i samband med kriget. Samtidigt är den betydligt mer omfattande i andra avseenden, exempelvis när det gäller den geografiska och ämnesmässiga bredden och genom den mångfald av teoretiska perspektiv som anläggs. Sammanlagt återfinns 19 artiklar som analyserar det första världskriget $i$ den brittiska och tyska såväl som i den nordamerikanska, kanadensiska och australiensiska barnlitteraturen. Eftersom boken inte begränsar sig till barnlittera- 
tur, utan också behandlar andra barnkulturella företeelser, utforskas även praktiker runt barn under krigsåren i en betydligt vidare mening, i utbildningsväsendet, i scoutrörelsen och på fritiden. Ett sådant kulturanalytiskt perspektiv blir tydligt i Emer O'Sullivans analys av barns sätt att leka krig, men också i Rachel Duffetts text som beskriver vad som hände med tillverkningen av krigsleksaker i England när dessa av olika skäl inte längre gick att importera från Tyskland. Barbara Cookes bidrag berör i sin tur mansidealen på en engelsk internatskola och Andrew Donson skildrar hur livet såg ut för unga flickor i Tyskland under kriget. Tillsammans tecknar dessa artiklar en bild av tiden som berikar förståelsen av barnlitteraturens roll i detta specifika historiska sammanhang, även om den barnlitterära texten inte alltid är artiklarnas huvudsakliga fokus.

För den som är intresserad av frågor som rör barnlitteraturens förhållande till det första världskriget finns här med andra ord åtskilligt att hämta. Men bredden för också med sig vissa svagheter. Antologin sträcker sig intressant nog över flera länders barnlitteraturer och kulturer, men det finns inte en tillräcklig systematik runt frågor som rör vilka språkområden som behandlas, varför de behandlas eller hur de förhåller sig till varandra. Det betyder naturligtvis inte att de olika antologibidragen är utan värde - de erbjuder en mångfacetterad förståelse av vad som kan kallas Barnets första världskrig. I jämförelse med Budgens bok är beskrivningen av den tidigare forskningen på området mer effektivt genomförd, särskilt i Lissa Pauls, Rosemary Ross Johnstons och Emma Shorts korta men klargörande introduktion. Själva menar de att den ständigt växande litteraturen om det första världskriget länge har saknat mer omfattande studier som synliggör barnets och barnkulturens betydelse för tolkningarna av denna viktiga historiska händelse. Tillsammans ger de två böckerna goda inblickar och åtskilligt med inspiration till den som fortsättningsvis önskar närma sig den spännande relationen mellan krig och barnlitteratur, exempelvis i vår nordiska kontext.

Olle Widhe

Docent i litteraturvetenskap

Göteborgs universitet 